\title{
Chronic cryptosporidiosis in patients with AIDS: stable remission and possible eradication after long term, low dose azithromycin
}

D Dionisio, A Orsi, G Sterrantino, M Meli, S Di Lollo, L Ibba Manneschi, M Trotta, M Pozzi, L Sani, F Leoncini

\begin{abstract}
Aims-To investigate the effectiveness of long term, low dose azithromycin treatment for chronic cryptosporidiosis in patients with AIDS.

Methods-Azithromycin was administered as initial daily treatment to 13 patients with AIDS: 6 patients received $500 \mathrm{mg}$ for 30 to 40 days (mean 35 ); 3 patients received $1000 \mathrm{mg}$ for 21 to 50 days (mean 37); and 4 patients received $1500 \mathrm{mg}$ for 20 days. Nine of the 13 patients were also given low dose maintenance treatment with different schedules of azithromycin for 30 to 360 days (mean 129). Patients were monitored, during and after treatment, for parasite shedding in stool and for daily stool frequency and body weight. All but one patient had severe immunodeficiency.

Results-Long term, low dose maintenance treatment was associated with major clinical and parasitological benefits: there was probable eradication of infection in 2 patients, and 7 patients showed a complete response with persistent high decrease ( 5 patients) or clearance (2 patients) of parasite in stool. The drug was well tolerated, and there was no relapse either during treatment or during follow up (up to 21 months). These results were more impressive than those observed after the short term initial course of azithromycin, which was unable at any tested dose to achieve parasite clearance in stool (except in the patient with less advanced immunodeficiency) or to prevent relapse in 3 patients who discontinued treatment. Reversible side effects occurred with the $1500 \mathrm{mg}$ daily dose.

Conclusions-Long term, low dose azithromycin is well tolerated and may induce stable remission of chronic cryptosporidiosis in patients with AIDS. It may lead to probable eradication of the infection in some patients, even those with severe immunodeficiency.

(F Clin Pathol 1998;51:138-142)
\end{abstract}

Keywords: cryptosporidiosis; AIDS; azithromycin

Cryptosporidiosis is a cause of chronic, sometimes life threatening, diarrhoea in about $15-40 \%$ of severely immunodeficient patients with AIDS..$^{1-3}$ There is currently no effective treatment for cryptosporidiosis in immuno- compromised patients; none of the available agents has been able to eradicate the infection or to induce stable clinical and parasitological remission..$^{1-5}$

Treatment failure can be explained by the fact that different chemotherapy is required for the early and the chronic phases of intestinal cryptosporidiosis. As seen in animal models, luminally active drugs can be sufficient to treat the early acute phase that involves the luminal surface of the gut during the first month of infection. ${ }^{6}$ However, drugs that are well absorbed through the intestinal mucosa and that are expected to have activity in the hepatobiliary tract are needed in the subsequent chronic phase. This phase is usually complicated by infection of the hepatobiliary tract and by formation of abscesses, with obliteration of intestinal crypts and stomach pits deeply harbouring parasite forms that become inaccessible to luminal treatment. ${ }^{6}$ Similar mechanisms are likely to be operating in man. Furthermore, biliary cryptosporidiosis is known to be a common source of reinfection in immunodeficient patients with AIDS. $^{78}$

Treatment failure can be also explained by the fact that many tested drugs have reduced activity at the low $\mathrm{pH}$ of the stomach and low concentrations in the terminal ileum and caecum, which are the areas of highest infection. ${ }^{4}$ Paromomycin, the most commonly used drug, has these limitations and is effective in no more than $30 \%$ of AIDS patients. ${ }^{49}$ Among other drugs that have been tested for human cryptosporidiosis, the macrolide azithromycin exhibits a more appropriate pharmacological profile, and has been well tolerated in humans. ${ }^{10}$

Following oral administration, azithromycin is well absorbed and widely distributed in tissues where its concentrations largely exceed that in serum, and its antimicrobial activity persists because of its slow release. ${ }^{10}$ Moreover, most of the absorbed drug remains unmetabolised, being excreted in faeces via the biliary tract (at concentrations higher than in serum), and by the transintestinal route. ${ }^{10}$ Based on these data, effective concentrations of azithromycin are expected to be reached in the hepatobiliary tract as well as in the terminal ileum and caecum.

Anticryptosporidial activity of azithromycin has been demonstrated in vitro, ${ }^{11}$ and the drug has high dose dependent effectiveness in the prevention and treatment of ileal, caecal, and biliary cryptosporidiosis of immunosuppressed 
rats, although eradication was not achieved with the schedules of treatment used in these experiments. ${ }^{9} 12$

In man, the results of azithromycin treatment for cryptosporidiosis are conflicting; however, there have been reported successes in immunocompromised children and suggestion of clinical and parasitological responses in AIDS patients after short term treatment, especially with high doses. ${ }^{1-3} 5$ 13-16

To our knowledge, no long term azithromycin treatment for AIDS related cryptosporidiosis has been reported in the literature, although data from animal models suggest that long term continuous administration may be necessary in the immunocompromised host. ${ }^{12}$ We provided long term, low dose azithromycin treatment for chronic cryptosporidiosis in immunodeficient patients with AIDS, and our results suggest that this regimen may induce stable remission of the infection, and may lead to eradication in some cases.

\section{Patients and methods}

Thirteen HIV infected patients $(11$ male, 2 female) with chronic cryptosporidiosis were studied. All but one patient had previously had standard courses with paromomycin ${ }^{4}$ leading to only transient symptomatic relief, with relapse occurring a few days after the treatment was discontinued. The patients were aged between 30 and 47 years (mean 35.6). Nine patients were homosexual and four were drug addicts. CD4+ $\mathrm{T}$ cell count ranged from $0-85 \times 10^{6} / 1$ in 12 patients (mean 24.3); it was $162 \times 10^{6} / 1$ in the other patient. All 13 patients had AIDS at the time of study entry; AIDS defining events were cryptosporidiosis in eight cases, and oesophageal candidiasis, cytomegalovirus infection, pneumocystosis, systemic Mycobacterium avium infection, and Kaposi's sarcoma in the other five cases, respectively. All patients had chronic diarrhoea (at least two months) with a range of 3-10 watery stools each day (mean 6). Weight loss ranged from 5-17 kg (mean 9).

Stools were processed by modified acid-fast staining to detect cryptosporidia. ${ }^{17}$ The amount of oocyst shedding was evaluated by a semiquantitative method on 100 microscopic fields: oocysts were defined as very frequent if present in every field, frequent if present in more than 50 but fewer than 100 fields, rare if present in fewer than 50 fields, and very rare if sporadically present. Before study entry, frequent to very frequent oocysts of cryptosporidium were present in all patients' stool. ${ }^{18}$ All patients had diagnosis confirmed by light and transmission electron microscopy of endoscopic biopsy specimens taken from the third tract of the duodenum. Stool samples were also examined for bacteria, Clostridium difficile toxin, mycobacteria, mycetes, adenoviruses and rotaviruses, microsporidia, and other parasites, with positive results in two patients who had Aeromonas hydrophila and Giardia lamblia, respectively.

All patients underwent a baseline evaluation that included full blood cell count, urine analy- sis, electrolytes, liver function tests, and abdominal ultrasonography.

Azithromycin was administered orally to all patients who were divided into three groups: group A received $500 \mathrm{mg}$ daily (6 patients), group B received $1000 \mathrm{mg}$ daily (3 patients), and group C received $1500 \mathrm{mg}$ daily (4 patients) (table 1). Assignment to each group and length of treatment were based on patient compliance and concurrent treatments for coexisting diseases. Four of the 13 patients did not continue into maintenance treatment because of the severity of coexisting diseases (cases 4,5, and 9) or the probable eradication after initial treatment (case 7). The remaining 9 patients (4 from group A, 1 from group B, and all 4 patients from group C) continued azithromycin into maintenance treatment with different schedules of treatment for 30 to 360 days (mean 129) (table 2). Again, assignment to each schedule was based on patient compliance and concurrent treatments for coexisting diseases. Three patients who had chosen to stop treatment after the initial course (cases 8, 11 , and 12), began maintenance treatment after relapse.

Written informed consent was obtained before treatment. No concomitant antidiarrhoeal drugs were administered. Clinical assessment, and haematological and liver function tests were monitored at 10 day intervals during treatment. At the end of treatment, CD4+ $\mathrm{T}$ cell count was repeated in patients who had received treatment for longer than three months. ${ }^{19}$ Adverse events were evaluated. Response to treatment was monitored by the search for oocysts in stool (one sample each day for three days) twice monthly during treatment and monthly after treatment, and by charting daily stool frequency and body weight.

A complete response was defined as cessation of diarrhoea (stool frequency less than three times each day), stabilisation of body weight, and significant decrease or clearance of oocyst shedding in stool lasting less than one year. A partial response was defined as more than $50 \%$ reduction in baseline stool frequency, with continuing weight loss, and either slight or no decrease of oocyst shedding in stool. No response was defined as no improvement in either clinical or parasitological baseline parameters. Probable eradication was defined as normal bowel movements with formed stool, stabilisation of body weight to preinfection level, and oocyst clearance in stool lasting at least one year.

\section{Results}

INITIAL TREATMENT

A complete response was observed in 10 patients ( 5 from group A, 2 from group B, and 3 from group C) (table 1). The remaining three patients showed partial response, no response, and probable eradication, respectively (table 1).

In the 10 patients who responded completely, a clinical response was obtained 1-30 days from starting treatment (mean 6.8), while a parasitological response (very rare faecal oocysts) was observed from 14-30 days (mean 
18.4). Case 1 also showed relief from coexisting acalcolous cholecystitis (unresponsive to previous paromomycin courses) from the third day of treatment, supporting a probable cryptosporidial aetiology. No differences in the time to a complete response, either clinical or parasitological, were documented among the three study groups.

Probable eradication was achieved by a 21 day course of $1000 \mathrm{mg}$ azithromycin daily in the patient with a CD4+ $\mathrm{T}$ cell count of $162 \times 10^{6} / 1$ (case 7 ). In this case, diarrhoea ceased a week after starting treatment, and oocyst clearance in stool, with gain in body weight, was evident from the end of treatment. Neither clinical nor parasitological relapse was documented until the patient's death one year later from tuberculosis.

A partial response was observed in a patient receiving $500 \mathrm{mg}$ daily for 40 days (case 4): daily stools decreased from 8 to 3 from the second day of treatment, and faecal oocysts decreased from very frequent to frequent three weeks after starting treatment.

There was no apparent response in a patient receiving $1500 \mathrm{mg}$ daily for 20 days (case 10). In this case, the parasite load in stool did not decrease, and side effects, such as worsening of diarrhoea (up to 15 watery stools each day) and abdominal cramps, were observed during treatment. These side effects, however, promptly reversed by restarting azithromycin at a lower daily dose (table 2). The same side effects, although less pronounced, were transiently present in two other patients also receiving azithromycin $1500 \mathrm{mg}$ daily (cases 12 and 13). No adverse reactions were documented in patients receiving lower daily doses of azithromycin.

Table 1 Results of initial treatment with azithromycin

\begin{tabular}{|c|c|c|c|c|c|c|}
\hline Case & $\begin{array}{l}\text { CD4 count } \\
\left(\times 10^{6} / l\right)\end{array}$ & $\begin{array}{l}\text { Length of } \\
\text { treatment } \\
\text { (days) }\end{array}$ & Response & Follow up & Maintenance & Cause of death \\
\hline \multicolumn{7}{|c|}{ Group A (500 mg daily) } \\
\hline 1 & 0 & 30 & $\mathrm{CR}$ & & Yes & \\
\hline 2 & 47 & 30 & $\mathrm{CR}$ & & Yes & \\
\hline 3 & 0 & 30 & CR & & Yes & \\
\hline 4 & 16 & 40 & PR & $\begin{array}{l}\text { No relapse until death } \\
\text { (just after end of } \\
\text { treatment) }\end{array}$ & No & Pneumonia \\
\hline 5 & 8 & 40 & CR & $\begin{array}{l}\text { No relapse until death } \\
\text { ( } 30 \text { days after end of } \\
\text { treatment) }\end{array}$ & No & Cytomegalovirus infection \\
\hline 6 & 42 & 40 & CR & & Yes & \\
\hline \multicolumn{7}{|c|}{ Group B (1000 mg daily) } \\
\hline 7 & 162 & 21 & PER & $\begin{array}{l}\text { No relapse until death } \\
\text { (1 year after end of } \\
\text { treatment) }\end{array}$ & No & Tuberculosis \\
\hline 8 & 6 & 40 & $\mathrm{CR}$ & $\begin{array}{l}\text { Relapse } 21 \text { days after } \\
\text { end of treatment }\end{array}$ & $\begin{array}{l}\text { Yes (after } \\
\text { relapse) }\end{array}$ & \\
\hline 9 & 2 & 50 & CR & $\begin{array}{l}\text { No relapse until death } \\
\text { (90 days after end of } \\
\text { treatment) }\end{array}$ & No & $\begin{array}{l}\text { Progressive multifocal } \\
\text { leukoencephalopathy }\end{array}$ \\
\hline \multicolumn{7}{|c|}{ Group C (1500 mg daily) } \\
\hline 10 & 52 & 20 & NR & & Yes & \\
\hline 11 & 5 & 20 & CR & $\begin{array}{l}\text { Relapse } 28 \text { days after } \\
\text { end of treatment }\end{array}$ & $\begin{array}{l}\text { Yes (after } \\
\text { relapse) }\end{array}$ & \\
\hline 12 & 29 & 20 & CR & $\begin{array}{l}\text { Relapse } 49 \text { days after } \\
\text { end of treatment }\end{array}$ & $\begin{array}{l}\text { Yes (after } \\
\text { relapse) }\end{array}$ & \\
\hline 13 & 85 & 20 & $\mathrm{CR}$ & & Yes & \\
\hline
\end{tabular}

CR, complete response; PR, partial response; PER, probable eradication; NR, no response.

Table 2 Maintenance treatment with azithromycin

\begin{tabular}{|c|c|c|c|c|c|}
\hline Case & Dose & $\begin{array}{l}\text { Length of } \\
\text { treatment } \\
\text { (days) }\end{array}$ & Response & Follow up & Cause of death \\
\hline 1 & $500 \mathrm{mg} 3$ days/week & 60 & $\mathrm{CR}$ & $\begin{array}{l}\text { No relapse until death (just } \\
\text { after end of treatment) }\end{array}$ & CNS toxoplasmosis \\
\hline 2 & $500 \mathrm{mg} 3$ days/week & 90 & CR & $\begin{array}{l}\text { No relapse until death ( } 30 \\
\text { days after end of } \\
\text { treatment) }\end{array}$ & Suicide \\
\hline 3 & $500 \mathrm{mg} 3$ days/week & 90 & $\mathrm{CR}$ & $\begin{array}{l}\text { No relapse until death ( } 30 \\
\text { days after end of } \\
\text { treatment) }\end{array}$ & $M$ avium infection \\
\hline 6 & $500 \mathrm{mg}$ daily & 170 & CR & $\begin{array}{l}\text { No relapse until death ( } 45 \\
\text { days after end of } \\
\text { treatment) }\end{array}$ & $\begin{array}{l}\text { Cytomegalovirus } \\
\text { infection }\end{array}$ \\
\hline 8 & $500 \mathrm{mg} 3$ days/week & 360 & CR & $\begin{array}{l}\text { No relapse } 8 \text { months after } \\
\text { end of treatment }\end{array}$ & \\
\hline 10 & $500 \mathrm{mg}$ daily & 30 & PER & $\begin{array}{l}\text { No relapse } 21 \text { months after } \\
\text { end of treatment }\end{array}$ & \\
\hline 11 & $\begin{array}{l}500 \mathrm{mg} \text { daily, followed by } \\
500 \mathrm{mg} 5 \text { days/week }\end{array}$ & $30+120(150)$ & $\begin{array}{l}\mathrm{CR} \text { (parasite } \\
\text { clearance) }\end{array}$ & $\begin{array}{l}\text { No relapse } 6 \text { months after } \\
\text { end of treatment }\end{array}$ & \\
\hline 12 & $\begin{array}{l}500 \mathrm{mg} \text { daily, followed by } \\
500 \mathrm{mg} 3 \text { days/week }\end{array}$ & $30+90(120)$ & PER & $\begin{array}{l}\text { No relapse } 14 \text { months after } \\
\text { end of treatment }\end{array}$ & \\
\hline 13 & $500 \mathrm{mg}$ daily & 90 & $\begin{array}{l}\text { CR (parasite } \\
\text { clearance) }\end{array}$ & $\begin{array}{l}\text { No relapse until death ( } 30 \\
\text { days after end of } \\
\text { treatment) }\end{array}$ & Kaposi’s sarcoma \\
\hline
\end{tabular}


Table 3 Coexisting diseases

\begin{tabular}{lll}
\hline Case & Disease & Treatment \\
\hline 1 & Kaposi's sarcoma (systemic) & None \\
& Cytomegalovirus infection (systemic) & Ganciclovir \\
& Toxoplasmosis (CNS) & Cotrimoxazole \\
& Staphylococcus epidermidis infection (sepsis) & Vancomycin \\
& Giardiasis (intestine) & Albendazole \\
2 & Candidiasis (mouth, oesophagus) & Fluconazole \\
& Mycobacterium xenopi infection (lung) & None \\
3 & Candidiasis (mouth) & Fluconazole \\
& Mycobacterium avium infection (systemic) & Rifabutin, clofazimine, ethambutol \\
4 & Candidiasis (oesophagus) & Fluconazole \\
& Kaposi's sarcoma (systemic) & None \\
5 & Candidiasis (oesophagus) & Fluconazole \\
& Kaposi's sarcoma (systemic) & None \\
& Cytomegalovirus infection (eye, rectum) & Ganciclovir, foscarnet \\
6 & Candidiasis (oesophagus) & Fluconazole \\
& Cytomegalovirus infection (eye) & Ganciclovir, foscarnet \\
& Aeromonas hydrophila infection (intestine) & Ciprofloxacin \\
7 & Tuberculosis (lung) & Isoniazide, rifampin, ethambutol, \\
& & streptomycin \\
8 & Candidiasis (mouth) & Fluconazole \\
& Kaposi's sarcoma (systemic) & None \\
9 & Candidiasis (oesophagus) & Fluconazole \\
& Progressive multifocal leukoencephalopathy & None \\
\multirow{2}{*}{10} & (CNS) & \\
11 & Candidiasis (oesophagus) & Fluconazole \\
\multirow{2}{*}{12} & Candidiasis (oesophagus) & Fluconazole \\
13 & Citrobacter freundii abscess (perianal) & Ganciclovir \\
& Candidiasis (oesophagus) & Surgical drainage, ciprofloxacin \\
& Kaposi's sarcoma (systemic) & Fluconazole \\
\hline & & None \\
& &
\end{tabular}

Three patients (cases 8,11 , and 12) relapsed 21,28 , and 49 days after treatment was discontinued, respectively, while two others (cases 5, and 9) showed no relapse until death 30 and 90 days after completion of treatment, respectively (table 1).

MAINTENANCE TREATMENT

Nine of the 13 patients continued into long term maintenance treatment with four schedules of treatment (table 2): azithromycin was administered at $500 \mathrm{mg} 3$ days each week to 3 patients from group A (cases 1, 2, and 3), and to 1 patient from group $B$ (case 8); at $500 \mathrm{mg}$ daily to 1 patient from group A (case 6), and to 2 patients from group $C$ (cases 10 , and 13); at $500 \mathrm{mg}$ daily for 30 days, followed by $500 \mathrm{mg} 5$ days each week, to 1 patient from group C (case 11); and at $500 \mathrm{mg}$ daily for 30 days, followed by $500 \mathrm{mg} 3$ days each week to another patient from group C (case 12). All schedules of treatment were well tolerated.

Complete response was observed in 7 patients and probable eradication in 2 patients (table 2).

Cases 1, 2, 3, 6, and 13 had a persistent complete response, with no relapse until death (table 2). Furthermore, case 13 also showed clearance of parasite in stool lasting until death. No symptomatic reactivation of acalcolous cholecystitis was documented in case 1 until death.

Case 8, who received maintenance treatment for one year, was still free from symptoms, and with a low parasite load in stool, eight months after interruption of treatment (table 2).

Case 11 achieved parasite clearance five months from starting maintenance treatment, and was still free from symptoms, with no oocysts in stool, six months after interruption of treatment (table 2).

The infection was probably eradicated in cases 10 and 12; there was parasite clearance from stool 30 and 120 days from starting maintenance treatment, respectively. Both patients recovered their preinfection weight and remained asymptomatic with no oocysts in stool, 21 and 14 months after completion of treatment, respectively (table 2).

During the whole course of azithromycin, several coexisting diseases developed in each patient (table 3), and no improvement in CD4+ T cell count was documented.

\section{Discussion}

Azithromycin has been tested in clinical trials for cryptosporidiosis in immunocompromised patients; however, in all these studies the drug was used for short term treatment. ${ }^{1-3} 5^{13-16}$ To our knowledge, this is the first trial showing results after long term treatment.

Long term, low dose azithromycin treatment was associated with pronounced clinical and parasitological benefit in nine severely immunodeficient patients with AIDS: two patients probably had the infection eradicated, and seven patients showed a persistent complete response with high decrease (five patients) or clearance (two patients) of parasite in stool. The drug was well tolerated, and there was no relapse, either during treatment or many months after treatment.

These results are more impressive than those we observed after short term initial azithromycin. The initial course, although associated with both clinical and parasitological benefit, was unable to achieve parasite clearance in stool (except in one patient with less advanced immunodeficiency), or to prevent relapse in the three patients who discontinued treatment. Azithromycin at high doses did not give better results than at low doses, and reversible side effects occurred with the $1500 \mathrm{mg}$ daily dose.

Our results are in agreement with those obtained in animal models of cryptosporidiosis that emphasise the need for long term continuous administration of azithromycin in immunocompromised hosts. ${ }^{12}$ Our results suggest that low dose long term azithromycin treatment would be adequate to avoid relapse and, possibly, to achieve eradication of chronic cryptosporidiosis in some patients with extremely low CD4+ $\mathrm{T}$ cell counts. Our data indicate that low dose, long term azithromycin can give better results than standard paromomycin, which is known to allow relapses either during or shortly after stopping treatment. ${ }^{1-3}$

The regimen we used required long term treatment, but azithromycin was well tolerated, adverse reactions occurred only with the highest dose (1500 mg daily), and promptly reversed when a lower dose was started. These data are in agreement with the literature, showing good tolerance of azithromycin in man, ${ }^{10}$ and support its safety for chronic use. The effects on cryptosporidiosis were obtained despite the fact that several opportunistic infections developed during the course of treatment, and no improvement in CD4+ $\mathrm{T}$ cell count was documented.

In spite of its small size, this study supports the effectiveness and safety of azithromycin for treating chronic cryptosporidiosis in patients 
with AIDS, and highlights the importance of long term, low dose treatment to prevent relapses and possibly achieve eradication of the infection, even in patients with severe immunodeficiency. These results could help to explain the controversial responses reported in the literature after short term treatment with azithromycin. ${ }^{3}$

Randomised controlled trials are required to confirm our preliminary results and to disperse doubts of spontaneous remission or improvement because of treatments for concomitant infections. These events, although possible, are unlikely as symptomatic cryptosporidiosis was chronic (many months in most patients) and showed no spontaneous remission before drug treatment, while there was a pronounced response to azithromycin. Moreover, to our knowledge, none of the drugs we used to treat concomitant infections (table 3) are reported to have activity against cryptosporidium.

As no patient had a gut biopsy after treatment, eradication is difficult to prove. ${ }^{16} 20$ However, the infection was probably eradicated in three patients (cases 7, 10, and 12) as they showed parasite clearance in stool during long term follow up (at least one year) based on a monthly search for oocysts with collection of one stool sample a day for three days. ${ }^{20}$ Furthermore, during this period bowel movements were normal and body weight increased to preinfection levels.

The authors are grateful to nurses Ada Mencherini and Meri Massoni for technical assistance.

1 Mannheimer SB, Soave R. Protozoal infections in patients with AIDS. Cryptosporidiosis, isosporiasis, cyclosporiasis and microsporidiosis. In: Management of infection in HIV disease. Infect Dis Clin North Am 1994;8:483-98.
2 Adal KA. From Wisconsin to Nepal: cryptosporidium, cyclospora, and microsporidia. Curr Opin Infect Dis 1994;7: cyclospora, $609-15$.

3 Beeching NJ. Chemotherapy of intestinal parasitoses. Curr Opin Infect Dis 1994;7:685-91.

4 Goodgame RW. Diagnosis and treatment of gastrointestinal protozoal infections. Curr Opin Infect Dis 1996;9:346-52.

5 Ritchie DJ, Becker ES. Update on the management of intesinal cryptosporidiosis in AIDS. Ann Pharmacother 1994; 28:767-78.

6 Tzipori S, Rand W, Theodos C. Evaluation of a two-phase scid mouse model preconditioned with anti-interferon- $\gamma$ monoclonal antibody for drug testing against Cryptosporidium parvum. F Infect Dis 1995;172:1160-4.

7 Benhamou Y, Caumes E, Gerosa Y, et al. AIDS-related cholangiopathy: critical analysis of a prospective series of 26 patients. Dig Dis Sci 1993;38:1113-18.

8 Goldin RD, Hunt J. Biliary tract pathology in patients with AIDS. f Clin Pathol 1993;46:691-3.

9 Rehg JE. A comparison of anticryptosporidial activity of paromomycin with that of other aminoglycosides and azithromycin in immunosuppressed rats. F Infect Dis 1994; 170:934-8.

10 Steigbigel $\mathrm{NH}$. Macrolides and clindamycin. In: Mandell GL, Bennett JE, Dolin R, eds. Principles and practice of infectious diseases. New York: Churchill Livingstone, 1995:33446.

11 Cirioni O, Giacometti A, Balducci M, et al. Anticryptosporidial activity of paromomycin. F Infect Dis 1995;172 $1169-70$.

12 Rehg JE. Activity of azithromycin against cryptosporidia in immunosuppressed rats. F Infect Dis 1991;163:1293-6.

13 Vargas SL, Shenep JL, Flynn PM, et al. Azithromycin for treatment of severe cryptosporidium diarrhea in two treatment of severe cryptosporidium diarrh
children with cancer. 7 Pediatr 1993;123:154-6.

14 Hicks P, Zwiener RJ, Squires J, et al. Azithromycin therapy for Cryptosporidium parvum infection in four children infected with human immunodeficiency virus. $f$ Pediatr 1996;129:297-300.

15 Dupont C, Bougnoux ME, Turner L, et al. Microbiological findings about pulmonary cryptosporidiosis in two AIDS patients. $\mathcal{F}$ Clin Microbiol 1996;34:227-9.

16 Blanshard C, Shanson DC, Gazzard BG. Pilot studies of azithromycin, letrazuril and paromomycin in the treatment of cryptosporidiosis. Int $\mathcal{F}$ STD AIDS 1997;2:124-9.

17 Garcia LS, Bruckner DA, Brewer TC, et al. Techniques for the recovery and identification of cryptosporidium oocysts from stool specimens. $\mathcal{F}$ Clin Microbiol 1983;18:185-90.

18 Goodgame RW, Genta RM, White AC, et al. Intensity of infection in AIDS-associated cryptosporidiosis. F Infect Dis infection in AIDS-

19 Flanigan T, Whalen C, Turner J, et al. Cryptosporidium infection and CD4 counts. Ann Intern Med 1992;116:840infectic

20 Blanshard C, Francis N, Gazzard BG. Investigation of chronic diarrhea in acquired immunodeficiency syndrome. A prospective study of 155 patients. Gut 1996;39:824-32. 